OPEN ACCESS

Edited by:

Alexander G. Ophir,

Cornell University, United States

Reviewed by:

Ivar Folstad,

UiT The Arctic University of Norway,

Norway

Andreas Walzer,

Universität für Bodenkultur Wien,

Austria

*Correspondence:

Hope Klug

hope-klug@utc.edu

Specialty section:

This article was submitted to Behavioral and Evolutionary Ecology,

a section of the journal

Frontiers in Ecology and Evolution

Received: 11 January 2018

Accepted: 13 March 2018

Published: 29 March 2018

Citation:

Klug H (2018) Why Monogamy? A Review of Potential Ultimate Drivers.

Front. Ecol. Evol. 6:30.

doi: $10.3389 /$ fevo.2018.00030

\section{Why Monogamy? A Review of Potential Ultimate Drivers}

\author{
Hope Klug* \\ Department of Biology, Geology, and Environmental Science, University of Tennessee at Chattanooga, Chattanooga, TN, \\ United States
}

The existence of monogamy in animals is perplexing from an evolutionary perspective. If individuals: (1) have the opportunity to mate with more than one individual and (2) doing so provides fitness benefits (e.g., indirect benefits, increased mating success or fecundity), why does monogamy ever occur in animals? To address this question, we must examine how the potential benefits and costs of monogamy differ between the sexes and how such costs and benefits interact with factors including resource availability, offspring need, parental care, and mating dynamics (i.e., the costs and benefits associated with acquiring mates and mate availability). In this review, I examine the interplay between parental and offspring dynamics, resource availability and mate distribution, and mating dynamics. In doing so, I highlight the life history and ecological conditions under which monogamy is expected vs. not. I then discuss areas of research that are needed to enhance our evolutionary understanding of monogamy. In particular, enhanced understanding of monogamy will come from: (1) more explicit consideration that the factors that lead to the origin of monogamy vs. the maintenance of monogamy might differ and (2) identifying how potential interactions among factors influence the origin and/or maintenance of monogamy.

Keywords: monogamy, parental care, parental investment, sexual selection, life history, mating system

\section{MONOGAMY IS AN EVOLUTIONARY CONUNDRUM}

Multiple mating is frequently associated with fitness benefits in both sexes. For example, Bateman (1948) found that male reproductive success is often limited by the number of female mates that a male acquires; as such, males are predicted to increase their lifetime reproductive success by mating with multiple females (Bateman, 1948; Jones and Ratterman, 2009). The expectation that male reproductive success is highly dependent on male mating success has been used to explain male multiple mating in a range of taxonomic groups (Jones and Ratterman, 2009). Likewise, females frequently benefit from mating with multiple males. For instance, a meta-analysis in insects revealed that multiple mating provides direct benefits to females in terms of increased egg production and fertility (Arnqvist and Nilsson, 2000). Similarly, extra-pair paternity, which is a proxy for multiple mating, was associated with higher hatching success, and hence greater female reproductive success, across 113 bird species (Reding, 2015). Female multiple mating can also in some, but not all, cases be associated with infanticide avoidance (Hrdy, 1979) or indirect benefits (Blomqvist et al., 2002; García-González and Simmons, 2005).

Given that multiple mating is often associated with fitness benefits, the existence of monogamy is perplexing from an evolutionary perspective. Indeed, if individuals: (1) have the opportunity to mate multiply and (2) doing so provides fitness benefits (e.g., increased reproductive success; 
see also Thonhauser et al., 2014; for review of relevant hypotheses), why does monogamy ever occur in animals? To address this question from an ultimate perspective, we must consider whether multiple mating is always possible and explore the costs and benefits of multiple mating. If multiple mating is possible, monogamy would most generally be expected to occur when there are no benefits of multiple mating or when there are costs of multiple mating. Understanding how monogamy can be beneficial to individuals, and hence, persist in populations requires that we consider: (1) how the benefits and costs of monogamy differ between the sexes and (2) how such costs and benefits interact with factors such as resource availability, offspring need, parental care, and mating dynamics.

In this review, I focus on the ultimate causes of monogamy in animals. I first discuss operational definitions and classic hypotheses of monogamy; I then discuss more recent work that has focused on the evolutionary interplay between parental and offspring dynamics, resource availability, and mating dynamics.

\section{MONOGAMY: WHAT'S IN A NAME AND WHAT DO WE SEE IN NATURE?}

Monogamy occurs when individuals have one mate for their entire lifetime or some specified period of time, and monogamy has been classified as a mating system in which neither sex is able to monopolize additional members of the opposite sex (Emlen and Oring, 1977). Historically, monogamy was thought to occur primarily in birds, and Lack (1968) initially estimated that more than $90 \%$ of birds were monogamous. However, as molecular tools became more accessible, researchers began to discover that many species that were once thought to be monogamous mate multiply. For instance, in one of the first studies on this topic, Gowaty and Karlin (1984) found that at least 5\% of male and 15\% of female eastern bluebirds (Sialia sialis) were caring for at least one offspring that was not genetically theirs; such research was surprising at the time because eastern bluebirds were thought to be monogamous. Such studies led to a distinction between genetic and social monogamy (Gowaty, 1996). Social monogamy occurs when a male-female pair cohabit and/or form a pair bond for some specified period of time; social monogamy does not assume that the male-female pair is exclusive with regard to mating. In contrast, genetic monogamy assumes that a malefemale pair is exclusive for some specified period of time with regard to mating and fertilization, although the pair doesn't necessarily pairbond.

The distinction between social and genetic monogamy has led to a range of studies that have revealed unique combinations of genetic and social monogamy. For instance, the largemouth bass (Micropterus salmoides) is socially monogamous and exhibits near-genetic monogamy (DeWoody et al., 2000). Likewise, long-eared owls (Asio otus) are socially and genetically monogamous (Marks et al., 1999). Similarly, Kentish plovers (Charadrius alexandrines) tend to primarily, but not always, exhibit social and genetic monogamy (Küpper et al., 2004). In contrast, in the prairie vole (Microtus ochrogaster), most males form pairbonds and cohabit with a single female but also engage in extra-pair mating; thus, most, but not all, individuals engage in social but not genetic monogamy (Ophir et al., 2007, 2008a,b). In the pot-bellied seahorse (Hippocampus abdominalis) the opposite trend has been observed: despite social promiscuity (e.g., promiscuous courtship) and a lack of pairbonding, genetic monogamy has been observed (Wilson and Martin-Smith, 2007). Mating systems have also been found to be dynamic (e.g., Forsgren et al., 2004; Wilson and Martin-Smith, 2007), suggesting that in some systems, individuals that are socially and/or genetically monogamous at one point in time might adopt a different strategy under different ecological conditions. Indeed, genetic monogamy occurs across a range of animals, but there is often inter-specific variation in the extent to which genetic monogamy occurs (Table 1).

When we focus on understanding the occurrence of monogamy in nature, it is important to recognize that a mating system is a descriptor of population- or species-level dynamics. Individuals themselves can exhibit strategies that are consistent with a given mating system, and these individual-level strategies that are associated with a given mating system (e.g., a particular propensity to engage in monogamous courtship, monogamous mating, multiple mating) are traits that can experience and respond to selection. That is, such traits can evolve. In contrast, the mating system of a population is not a trait and can therefore not evolve in a biological sense; a mating system can change on short and long time scales and across spatial contexts, and a mating system can create selection pressures, but ultimately traits are what evolve biologically. In considering the factors that are hypothesized to influence monogamy (discussed below), it is important to keep in mind that mating systems are influenced by traits, which can evolve, and that a mating system can create selective pressures that lead to future evolution of relevant traits. This evolutionary interplay and feedback between mating systems and traits is likely key to understanding the variation in mating dynamics that exist in nature, and hence, key to understanding the occurrence of monogamy.

\section{CLASSIC PERSPECTIVES ON MONOGAMY}

\section{Resources, Parental Care, and Sexual Selection Matter}

Emlen and Oring (1977) were not the first to study mating systems (Darwin, 1888; Verner and Willson, 1966; Orians, 1969; Bartholomew, 1970), but the synthetic conceptual framework of mating systems that they developed was remarkably influential. Emlen and Oring (1977) hypothesized that there is a link between mating system and sexual selection and suggested that sexual selection will be relatively slight in monogamous systems (Figure 1). They emphasized that understanding diversity in mating systems requires that we understand the factors that influence sexual selection. Specifically, they suggested that sexual selection will be influenced by the "ability of a portion of the population to control the access of others to potential mates" and that monogamy will occur when there is "economic defendability of a mate" (Emlen and Oring, 1977; Figure 1). Emlen and 
TABLE 1 | Examples of monogamy in nature.

\begin{tabular}{ll}
\hline Animal type & Example of monogamy \\
\hline Fish & The bonnethead shark (Sphyrna tiburo) tends to exhibit within-litter \\
& genetic monogamy, despite the ability to store sperm, although in \\
& 19\% of cases, litters were sired by multiple males (Chapman et al., \\
& 2004). \\
& The mimic poison frog (Ranitomeya imitator) is the first known \\
Amphibian & example of a socially and genetically monogamous amphibian \\
& (Tumulty et al., 2013). \\
& The Australian lizard (Egernia stokesii) lives in stable groups of \\
Reptile & breeding pairs, and genetic monogamy is the most common \\
& mating strategy, although some litters had multiple paternity \\
& (Gardner et al., 2002). \\
Fird & Forida scrub-jays (Aphelocoma coerulescens), who breed \\
& although there are rare exceptions in which males have two female \\
& mates (Quinn et al., 1999). \\
& The Azara's owl monkey (Aotus azarae) is a pair-living primate with \\
bi-parental care that exhibits genetic monogamy (Huck et al., \\
2014).
\end{tabular}

Oring (1977) noted that critical non-mate resources will vary spatially and temporally and that this can affect the spatial and temporal distribution - and hence the defendability — of potential mates (Figure 1). They additionally predicted a link between biparental care and monogamy and noted that monogamy is most likely to occur when the potential for or the benefit of multiple mating is low (Figure 1). They hypothesized that under such conditions, individuals can increase their fitness by remaining with their current mate and increasing offspring survival.

More recent work (discussed below) has demonstrated that co-evolutionary feedback can occur and lead to patterns that are more complex than those initially predicted (e.g., we now know that sexual selection isn't always slight in monogamous systems; Jones and Hunter, 1993). Indeed, as noted by Wittenberger and Tilson (1980), no single hypothesis alone is sufficient to explain monogamy; instead a series of hypotheses and an understanding of when each should apply is required to understand monogamy (Wittenberger and Tilson, 1980). Nonetheless, the relatively simple verbal arguments of Emlen and Oring (1977) highlighted the key role that sexual selection, resources, and parental care can play in influencing monogamy.

\section{The Role of Female Benefits in Monogamous Mating Systems}

Wittenberger and Tilson (1980) expanded the conditions under which monogamy is expected. They focused more explicitly on the role that female fitness benefits have in maintaining monogamy and hypothesized that monogamous mating systems require: (1) female benefits of monogamous pair bonds that cannot be obtained in the absence of monogamy; (2) the ability of females to assess the mated status of males; and (3) a lack of male desertion. They additionally hypothesized that monogamy is most likely to occur when: (1) male parental care is essential and non-shareable among offspring; (2) the benefits of mating with a superior polygynous male do not outweigh the costs of polygyny that is associated with reduced parental care; (3) males achieve the greatest fitness benefits by mating with and defending a single female; (4) aggression by females occurs; and (5) increased competition for resources and/or increased predation associated with multiple female mates occurs (Wittenberger and Tilson, 1980). Importantly, these hypotheses are inter-related and not mutually exclusive.

In the years following the work of Emlen and Oring (1977) and Wittenberger and Tilson (1980), numerous authors refined the conditions under which monogamy is expected (e.g., Greenlaw and Post, 1985; Björklund and Westman, 1986; Mock and Fujioka, 1990). Many of these early studies that focused explicitly on monogamy utilized verbal arguments that were largely based on our knowledge of mating systems at the time (but see, e.g., mathematical models by Parker and Macnair, 1978 and McLean and Manning, 1985). Many of these early hypotheses have now been tested or expanded upon empirically and/or by using mathematical modeling. Below, I review the insights that such work has provided.

\section{RECENT PERSPECTIVES ON THE ORIGIN AND MAINTENANCE OF MONOGAMY}

\section{Parental Care Can Matter}

A frequent prediction of early work is that paternal care is associated with monogamy (Emlen and Oring, 1977; Wittenberger and Tilson, 1980; Gowaty, 1996; Figure 1). Indeed, some theoretical work has found that paternal care influences the occurrence of monogamy. Iwasa and Harada (1998) found that monogamy can occur when parental ability is the same between parents if females choose their mates and males invest in paternal care. If females and males vary in quality (i.e., fecundity and parental ability), this can lead to assortative mating and monogamy, although the mating dynamics will depend on the costs of care to males and variation in female fecundity (Iwasa and Harada, 1998). In animals, monogamy is often associated with bi-parental care, but whether bi-parental care precedes or follows the evolution of monogamy is debatable (reviewed in Brotherton and Komers, 2003 and discussed in section "But, Is Bi-parental Care Really Necessary for Monogamy”? below).

\section{Co-evolutionary Dynamics Matter}

More recent work has suggested that understanding the origin and persistence of any mating system, including monogamy, requires that we develop a framework that accounts for interactions among mating dynamics, parental investment, and costs of care, and mating (Figure 1). The likelihood of paternal care, which as discussed above is in some cases predicted to influence monogamy, is affected by a range of factors, including the costs and benefits of caring vs. competing for mates (Figure 1). Kokko and Jennions (2008) developed a model focused on sex roles that accounted for feedback associated with the costs and benefits of caring vs. competing for mates. Their work revealed that when providing parental care is associated with higher mortality than competing for mates, individuals of the deserting sex (i.e., the sex that provides no care) will become more common in the population and in turn have difficulty 


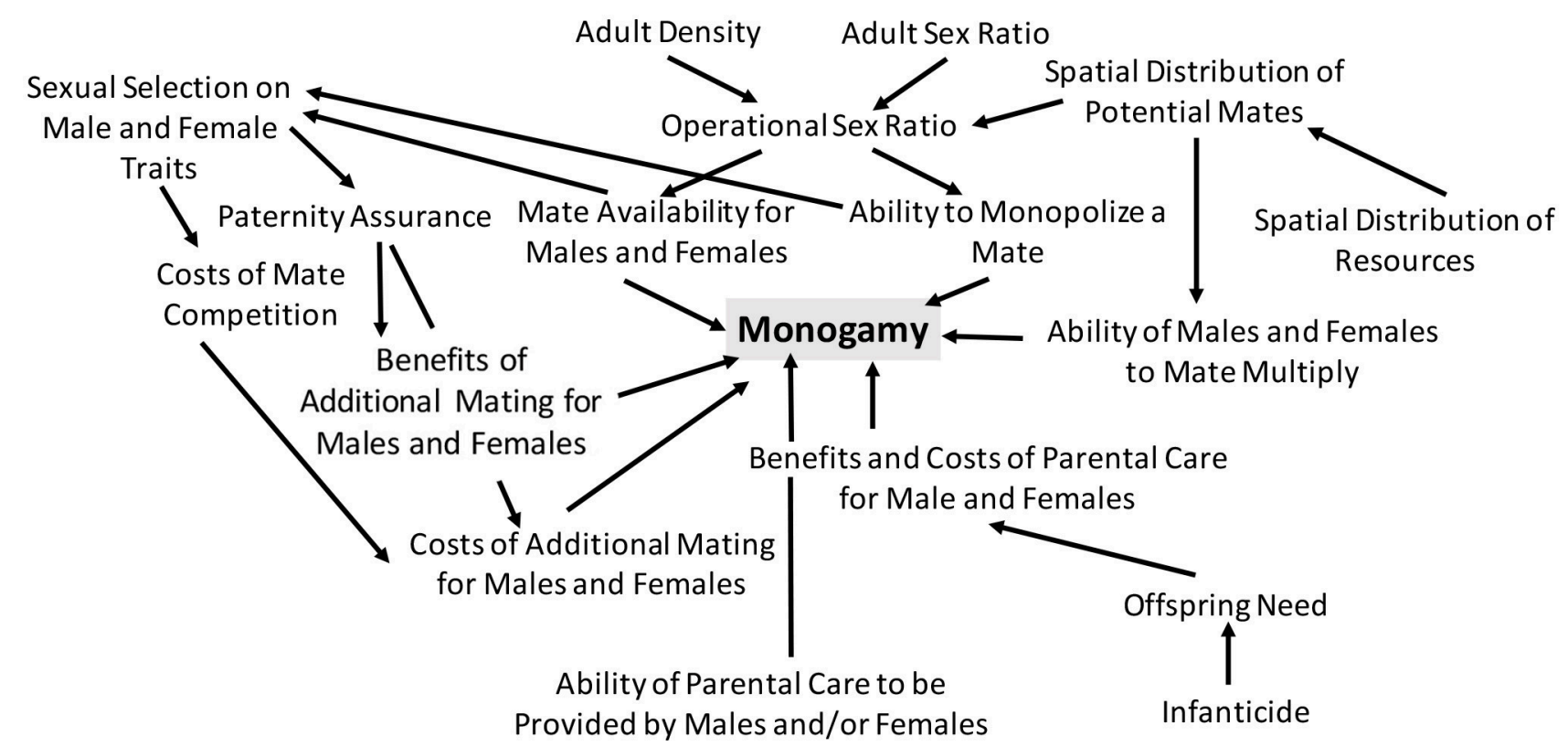

FIGURE 1 | It's complicated! An overview of the factors hypothesized to influence monogamy. Numerous factors are expected to influence the presence or absence of monogamy in animals, which is why multiple hypotheses are required to understand the occurrence of monogamy in nature. Here, I illustrate some of the key factors that are expected to influence whether or not monogamy occurs. This is not an exhaustive list, as additional factors are expected to influence monogamy in some cases, and this figure does not illustrate the feedback that is expected to occur between the various factors depicted below, as well as the co-evolutionary feedback that is expected to occur among traits associated with mating, parental investment, and mate and resource competition.

finding a mate; under such a scenario, across evolutionary time, we would expect (1) bi-parental care to be more likely and (2) for males and females to differ relatively little in the amount of care provided (Kokko and Jennions, 2008). While monogamy was not explicitly focused on in the modeling work of Kokko and Jennions (2008), if bi-parental care is associated with monogamy (see above), we might expect monogamy to be more likely in systems in which parental care is associated with high adult mortality.

\section{But, Is Bi-parental Care Really Necessary for Monogamy?}

While bi-parental care and monogamy commonly co-occur (reviewed in Brotherton and Komers, 2003), some researchers have questioned whether bi-parental care is necessary for, or rather a consequence of, monogamy. In humans, Schacht and Bell (2016) found that mate guarding rather than paternal care leads to monogamy, as monogamy allows males to maintain high paternity. Likewise, Lukas and Clutton-Brock (2013) suggested that in non-human mammals, male care is a consequence rather than a cause of monogamy. They instead suggested that monogamy is caused by low female density and the inability of males to defend multiple females. However, Dobson et al. (2010) found that socially monogamous and nonmonogamous mammals have similar local densities and home ranges, suggesting that local density and home range area might not be a primary driver of monogamy in all mammals. Instead, Dobson et al. (2010) suggested that the origin of monogamy in mammals is caused by a range of factors. In primates, Opie et al. (2013) found a correlation between social monogamy, female home range, and bi-parental care; however, their research suggests that infanticide is likely the key factor that leads to a shift toward social monogamy in primates.

In some cases, paternal care is decoupled from monogamy. In extreme cases, males die after mating and are thus unable to provide paternal care. Fromhage et al. (2005) found that monogyny can be favored in the absence of male care when monogyny increases paternity if the sex ratio is male biased. Thus, while bi-parental care and monogamy frequently co-occur, it does not appear that bi-parental care is always a pre-requisite for the origin or maintenance of monogamy. Indeed, in some cases mate guarding and paternity assurance can directly favor monogamy.

In summary, bi-parental care commonly co-occurs with monogamy, but the role that bi-parental care plays in driving the origin of monogamy is unclear, particularly in mammals.

\section{Interactions Between Ecology and Parental Care Can Lead to Monogamy}

While bi-parental care is not always essential for monogamy, parental care and offspring need can in some cases interact with ecological factors to drive the origin of monogamy. For instance, Brown et al. (2010) found that in frogs, a single ecological factor (breeding pool size) is related to the origin of care. In poison frogs, they found that feeding of offspring co-evolved with the use of small pools and that feeding behavior was associated with 
the origin of bi-parental care, as bi-parental care is essential to offspring survival in small (but not large) pools. Molecular and field analyzes revealed that social and genetic monogamy occur in Ranitomeya imitator, a species that utilizes small pools, but not Ranitomeya variabilis, a species that uses large pools, suggesting that an ecological factor (pool size) led to the co-evolution of bi-parental care and monogamy in R. imitator (Brown et al., 2010). These results highlight the important interactions that can occur between ecological factors, parental care, offspring need, and monogamy.

\section{PUTTING IS ALL TOGETHER: WHAT DRIVES THE ORIGIN AND MAINTENANCE OF MONOGAMY?}

Decades of empirical and theoretical research suggest that there is no single factor that drives monogamy across animals. This is perhaps not surprising given the immense variation in life history, evolutionary history, and ecological factors in animals. Numerous studies, however, have demonstrated that the following likely influence monogamy: (1) spatial and temporal distribution of females, (2) parental care costs and benefits, (3) offspring need, (4) infanticide, (5) costs and benefits of multiple mating, (7) mate competition, (8) paternity assurance, (9) the potential for mate guarding, and (10) resource use (Figure 1). This is a broad list, and the relative importance of each factor likely varies across systems. Additionally, the factors above are likely to interact. For example, ecology can affect mate distribution and offspring need; infanticide can affect offspring need; costs of parental care will influence mate availability, which will in turn affect benefits of mate searching. Additional research on such interactions warrants further attention (discussed below).

\section{WHAT'S NEXT?}

I suggest that there are two primary areas of research that are needed to more fully understand monogamy from an ultimate

\section{REFERENCES}

Arnqvist, G., and Nilsson, T. (2000). The evolution of polyandry: multiple mating and female fitness in insects. Animal Behav. 60, 145-164. doi: $10.1006 /$ anbe. 2000.1446

Bartholomew, G. A. (1970). A model for the evolution of pinniped polygyny. Evolution 24, 546-559. doi: 10.1111/j.1558-5646.1970.tb01790.x

Bateman, A. J. (1948). Intra-sexual selection in Drosophila. Heredity 2( $\mathrm{Pt} 3)$, 349-368. doi: 10.1038/hdy.1948.21

Björklund, M., and Westman, B. (1986). Adaptive advantages of monogamy in the great tit (Parus major): an experimental test of the polygyny threshold model. Animal behav. 34, 1436-1440. doi: 10.1016/S0003-3472(86)8 0214-7

Blomqvist, D., Andersson, M., Küpper, C., Cuthill, I. C., Kis, J., Lanctot, R. B., et al. (2002). Genetic similarity between mates and extra-pair parentage in three species of shorebirds. Nature 419, 613-615. doi: 10.1038/nature 01104 perspective. First, we need to recognize that the factors that promote the origin vs. the maintenance of monogamy might differ (see discussion in Gowaty, 1996). Within animals, it will be important to better understand if the factors that promote the origin of monogamy are the same (or different) than those that promote the maintenance of monogamy.

Second, it will be critical to better understand how life-history, ecological, and mating factors interact to influence monogamy. As mentioned earlier, monogamous mating dynamics can create selective pressures that influence evolutionary trajectories; for example, West (2014) found that the evolution of large brain size is associated with social but not genetic monogamy in birds. Likewise, Jašarević et al. (2013) found that monogamy can influence the evolution of female life histories in mammals. Further, previous work has found that mate guarding, male attractiveness, and paternity can interact in complicated ways to influence social monogamy (Kokko and Morrell, 2005). Recent studies have begun to focus on the interplay between such factors, but there is still more work to do in identifying the interactions (rather than the individual factors) that lead to the origin and maintenance of monogamy. Focusing on such interactions will likely also be necessary to better understand how monogamy varies within a population and through time. Indeed, understanding variation in the propensity to be monogamous within and across individuals of a population has received relatively little attention from an ultimate perspective and warrants future attention.

\section{AUTHOR CONTRIBUTIONS}

The author confirms being the sole contributor of this work and approved it for publication.

\section{ACKNOWLEDGMENTS}

This material is based upon work supported by the National Science Foundation under Grant No. 1552721. I am grateful to Dylan Hackett for his discussion and research on the ideas discussed herein.
Brotherton, P. N., and Komers, P. E. (2003). "Mate guarding and the evolution of social monogamy in mammals," in Monogamy: Mating Strategies and Partnerships in Birds, Humans and Other Mammals, eds U. H. Reichard and C. Boesch (Cambridge: Cambridge University Press), 42-58.

Brown, J. L., Morales, V., and Summers, K. (2010). A key ecological trait drove the evolution of biparental care and monogamy in an amphibian. Am. Nat. 175, 436-446. doi: 10.1086/650727

Chapman, D. D., Prodöhl, P. A., Gelsleichter, J., Manire, C. A., and Shivji, M. S. (2004). Predominance of genetic monogamy by females in a hammerhead shark, Sphyrna tiburo: implications for shark conservation. Mol. Ecol. 13, 1965-1974. doi: 10.1111/j.1365-294X.2004.02178.x

Darwin, C. (1888). The Descent of Man and Selection in Relation to Sex, Vol. 1. Murray, UT.

DeWoody, J. A., Fletcher, D. E., Wilkins, S. D., Nelson, W. S., and Avise, J. C. (2000). Genetic monogamy and biparental care in an externally fertilizing fish, the largemouth bass (Micropterus salmoides). Proc. R. Soc. Lond. Biol. Sci. 267, 2431-2437. doi: 10.1098/rspb.2000.1302 
Dobson, F. S., Way, B. M., and Baudoin, C. (2010). Spatial dynamics and the evolution of social monogamy in mammals. Behav. Ecol. 21, 747-752. doi: 10.1093/beheco/arq048

Emlen, S. T., and Oring, L. W. (1977). Ecology, sexual selection, and the evolution of mating systems. Science 197, 215-223.

Forsgren, E., Amundsen, T., Borg, Å. A., and Bjelvenmark, J. (2004). Unusually dynamic sex roles in a fish. Nature $429,551-554$. doi: 10.1038/nature02562

Fromhage, L., Elgar, M. A., and Schneider, J. M. (2005). Faithful without care: the evolution of monogyny. Evolution 59, 1400-1405. doi: 10.1111/j.0014-3820.2005.tb01790.x

García-González, F., and Simmons, L. W. (2005). The evolution of polyandry: intrinsic sire effects contribute to embryo viability. J. Evol. Biol. 18, 1097-1103. doi: 10.1111/j.1420-9101.2005.00889.x

Gardner, M. G., Bull, C. M., and Cooper, S. J. B. (2002). High levels of genetic monogamy in the group-living Australian lizard Egernia stokesii. Mol. Ecol. 11, 1787-1794. doi: 10.1046/j.1365-294X.2002.01552.x

Gowaty, P. A. (1996). "Battles of the sexes and origins of monogamy," in Partnerships in Birds, ed J. M. Black (Oxford: Oxford University Press), 21-52.

Gowaty, P. A., and Karlin, A. A. (1984). Multiple maternity and paternity in single broods of apparently monogamous eastern bluebirds (Sialia sialis). Behav. Ecol. Sociobiol. 15, 91-95. doi: 10.1007/BF00299374

Greenlaw, J. S., and Post, W. (1985). Evolution of monogamy in seaside sparrows, Ammodramus maritimus: tests of hypotheses. Anim. Behav. 33, 373-383. doi: 10.1016/S0003-3472(85)80061-0

Hrdy, S. B. (1979). Infanticide among animals: a review, classification, and examination of the implications for the reproductive strategies of females. Ethol. Sociobiol. 1, 13-40. doi: 10.1016/0162-3095(79)90004-9

Huck, M., Fernandez-Duque, E., Babb, P., and Schurr, T. (2014). Correlates of genetic monogamy in socially monogamous mammals: insights from Azara's owl monkeys. Proc. R. Soc. Lond. Biol. Sci. 281:20140195. doi: $10.1098 /$ rspb.2014.0195

Iwasa, Y., and Harada, Y. (1998). Female mate preference to maximize paternal care. II. Female competition leads to monogamy. Am. Nat. 151, 367-382. doi: $10.1086 / 286125$

Jašarević, E., Bailey, D. H., Crossland, J. P., Dawson, W. D., Szalai, G., Ellersieck, M. R., et al. (2013). Evolution of monogamy, paternal investment, and female life history in Peromyscus. J. Comp. Psychol. 127, 91-102. doi: 10.1037/a00 27936

Jones, A. G., and Ratterman, N. L. (2009). Mate choice and sexual selection: what have we learned since Darwin? Proc. Natl. Acad. Sci. U.S.A. 106(Suppl. 1), 10001-10008. doi: 10.1073/pnas.0901129106

Jones, I. L., and Hunter, F. M. (1993). Mutual sexual selection in a monogamous seabird. Nature 362, 238-239. doi: 10.1038/362238a0

Kokko, H., and Jennions, M. D. (2008). Parental investment, sexual selection and sex ratios. J. Evol. Biol. 21, 919-948. doi: 10.1111/j.1420-9101.2008.01540.x

Kokko, H., and Morrell, L. J. (2005). Mate guarding, male attractiveness, and paternity under social monogamy. Behav. Ecol. 16, 724-731. doi: 10.1093/beheco/ari050

Küpper, C., Kis, J., Kosztolányi, A., Székely, T., Cuthill, I. C., and Blomqvist, D. (2004). Genetic mating system and timing of extra-pair fertilizations in the Kentish plover. Behav. Ecol. Sociobiol. 57, 32-39. doi: 10.1007/s00265-004-0832-3

Lack, D. (1968). Ecological Adaptations for Breeding in Birds. Methuen, MA: Chapman and Hall.

Lukas, D., and Clutton-Brock, T. H. (2013). The evolution of social monogamy in mammals. Science 341, 526-530. doi: 10.1126/science. 1238677
Marks, J. S., Dickinson, J. L., and Haydock, J. (1999). Genetic monogamy in long-eared owls. Condor 101, 854-859. doi: 10.2307/1370075

McLean, K. R., and Manning, J. T. (1985). Mate choice, monogamy and mutational load. J. Theor. Biol. 116, 369-376. doi: 10.1016/S0022-5193(85)80275-7

Mock, D. W., and Fujioka, M. (1990). Monogamy and long-term pair bonding in vertebrates. Trends Ecol. Evol. 5, 39-43. doi: 10.1016/0169-5347(90)90045-F

Ophir, A. G., Phelps, S. M., Sorin, A. B., and Wolff, J. O. (2008a). Social but not genetic monogamy is associated with greater breeding success in prairie voles. Anim. Behav. 75, 1143-1154. doi: 10.1016/j.anbehav.2007.09.022

Ophir, A. G., Phelps, S. M., Sorin, A. B., and Wolff, J. O. (2007). Morphological, genetic, and behavioral comparisons of two prairie vole populations in the field and laboratory. J. Mammal. 88, 989-999. doi: 10.1644/06-MAMM-A-250R.1

Ophir, A. G., Wolff, J. O., and Phelps, S. M. (2008b). Variation in neural VlaR predicts sexual fidelity and space use among male prairie voles in semi-natural settings. Proc. Natl. Acad. Sci.U.S.A. 105, 1249-1254. doi: 10.1073/pnas.0709116105

Opie, C., Atkinson, Q. D., Dunbar, R. I., and Shultz, S. (2013). Male infanticide leads to social monogamy in primates. Proc. Natl. Acad. Sci. U.S.A. 110, 13328-13332. doi: 10.1073/pnas.1307903110

Orians, G. H. (1969). On the evolution of mating systems in birds and mammals. Am. Nat. 103, 589-603. doi: 10.1086/282628

Parker, G. A., and Macnair, M. R. (1978). Models of parent-offspring conflict. I. Monogamy. Anim. Behav. 26, 97-110. doi: 10.1016/0003-3472(78)90009-X

Quinn, J. S., Woolfenden, G. E., Fitzpatrick, J. W., and White, B. N. (1999). Multilocus DNA fingerprinting supports genetic monogamy in Florida scrub-jays. Behav. Ecol. Sociobiol. 45, 1-10. doi: 10.1007/s002650050534

Reding, L. (2015). Increased hatching success as a direct benefit of polyandry in birds. Evolution 69, 264-270. doi: 10.1111/evo.12553

Schacht, R., and Bell, A. V. (2016). The evolution of monogamy in response to partner scarcity. Sci. Rep. 6:32472. doi: 10.1038/srep32472

Thonhauser, K. E., Thoß, M., Musolf, K., Klaus, T., and Penn, D. J. (2014). Multiple paternity in wild house mice (Mus musculus musculus): effects on offspring genetic diversity and body mass. Ecol. Evol. 4, 200-209. doi: 10.1002/ece3.920

Tumulty, J., Morales, V., and Summers, K. (2013). The biparental care hypothesis for the evolution of monogamy: experimental evidence in an amphibian. Behav. Ecol. 25, 262-270. doi: 10.1093/beheco/art116

Verner, J., and Willson, M. F. (1966). The influence of habitats on mating systems of North American passerine birds. Ecology 47, 143-147. doi: 10.2307/1935753

West, R. J. (2014). The evolution of large brain size in birds is related to social, not genetic, monogamy. Biol. J. Linn. Soc. 111, 668-678. doi: 10.1111/bij.12193

Wilson, A. B., and Martin-Smith, K. M. (2007). Genetic monogamy despite social promiscuity in the pot-bellied seahorse (Hippocampus abdominalis). Mol. Ecol. 16, 2345-2352. doi: 10.1111/j.1365-294X.2007.03243.x

Wittenberger, J. F., and Tilson, R. L. (1980). The evolution of monogamy: hypotheses and evidence. Annu. Rev. Ecol. Systemat. 11, 197-232. doi: 10.1146/annurev.es.11.110180.001213

Conflict of Interest Statement: The author declares that the research was conducted in the absence of any commercial or financial relationships that could be construed as a potential conflict of interest.

Copyright (c) $2018 \mathrm{Klug}$. This is an open-access article distributed under the terms of the Creative Commons Attribution License (CC BY). The use, distribution or reproduction in other forums is permitted, provided the original author(s) and the copyright owner are credited and that the original publication in this journal is cited, in accordance with accepted academic practice. No use, distribution or reproduction is permitted which does not comply with these terms. 